\title{
El "nuevo regionalismo" y el área de libre comercio de las Américas: un enfoque menos indulgente
}

\author{
R oberto Bouzas
}

$\square$

ste trabajo analiza las ventajas y desventajas del "nuevo regionalismo", tomando como referencia las negociaciones para la creación del Área de Libre Comercio de las Américas (ALCA). Sintetiza las principales características del "nuevo regionalismo" y examina algunos de los problemas y oportunidades que plantean los acuerdos de comercio preferencial norte-sur (una de las peculiaridades de los nuevos acuerdos de este tipo). Hace hincapié en el papel de las políticas nacionales como complemento de la liberalización comercial, un aspecto que generalmente se pasa por alto en el debate sobre las negociaciones y los acuerdos de comercio preferencial. Estudia la evolución de las negociaciones del ALCA, y en especial las más recientes tendencias y perspectivas, y por último, resume los principales temas planteados en el trabajo y pone de relieve las características preocupantes del ALCA que comienzan a esbozarse después de una década de negociaciones. 


\section{Introducción}

Los acuerdos de comercio preferente florecieron en el hemisferio occidental desde mediados del decenio de 1980. Transcurridas dos décadas de intensas negociaciones, la arquitectura de esta red de pactos todavía se está construyendo. La proliferación de este tipo de acuerdos en la región no es totalmente nueva, pero la modalidad de discriminación comercial difiere bastante de la del pasado y constituye lo que se ha llamado el "nuevo regionalismo". 1

Ya sea porque creen en sus ventajas o en su carácter de inevitable, muchos analistas han evaluado con indulgencia este "nuevo regionalismo", recalcando sus potenciales frutos y minimizando sus costos. Sólo algunos "librecambistas" — por lo general acusados de falta de "sentido práctico"- han alzado una voz crítica.

El objetivo de este trabajo es analizar las ventajas y desventajas del "nuevo regionalismo", tomando como referencia las negociaciones para la creación del Área de Libre Comercio de las Américas (ALCA), que es uno de sus exponentes principales y más complejos. Los problemas que surgen con respecto a su arquitectura y contenido regulador son representativos de los obstáculos y las oportunidades que ofrece la nueva modalidad de discriminación comercial. Un acuerdo preferencial hemisférico podría crear oportunidades comerciales para los países latinoamericanos y fomentar el desarrollo económico en todo el continente, pero esto no sucederá en forma automática. Las oportuni- dades que podría brindar el ALCA - como las que surgen de cualquier proceso de liberalización económica- son condicionales. Para que se materialicen, el acuerdo debe cumplir con ciertos requisitos y complementarse con políticas que permitan cosechar los frutos de una mayor competencia y especialización y del acceso a mercados más grandes. En este contexto, las negociaciones del ALCA presentan tendencias preocupantes.

Este artículo se divide en cinco secciones. Tras la presente sección introductoria, la sección II resume las principales características del "nuevo regionalismo" y examina algunos de los problemas y oportunidades que plantean los acuerdos de comercio preferencial norte-sur (una de las peculiaridades de los nuevos acuerdos de este tipo). En la sección III se hace hincapié en el papel de las políticas nacionales como complemento de la liberalización comercial y su función clave para aprovechar en forma efectiva las oportunidades ofrecidas por el "nuevo regionalismo", un aspecto que generalmente se pasa por alto en el debate sobre las negociaciones y acuerdos de comercio preferencial.

En la sección IV se estudia la evolución de las negociaciones del ALCA, atendiendo especialmente a las últimas tendencias y perspectivas. Y en la sección $\mathrm{V}$, por último, se hace una síntesis de los principales temas planteados en el trabajo, con el ánimo de comprender más que de prescribir.

\section{II \\ El "nuevo regionalismo" y los acuerdos de comercio preferencial norte-sur en el hemisferio occidental}

Deseo agradecer los valiosos comentarios realizados por un evaluador anónimo.

${ }^{1}$ En el extremo sur del hemisferio occidental el "nuevo regionalismo" fue inaugurado por el Programa de Intercambio y Cooperación Argentina-Brasil firmado en 1986 (un precedente del Mercosur), mientras que en el extremo norte el primer acuerdo fue el Tratado de libre comercio de Canadá y Estados Unidos (FTA).
La ola de negociaciones comerciales que se observó en el hemisferio occidental en los últimos 20 años es un ingrediente clave del llamado "nuevo regionalismo". ${ }^{2}$ Este proceso dio lugar a una compleja red de

\footnotetext{
2 De hecho, el "nuevo regionalismo" se ha extendido a todo el mundo. Inclusive Asia y el Pacífico, región que tradicionalmente
} 
acuerdos de comercio preferencial, intrincada maraña que Bhagwati (1993) denominó "spaghetti bowl". Aunque a primera vista —por lo menos en América Latina- no es muy diferente del llamado "viejo regionalismo", el "nuevo regionalismo" se vio acompañado de cambios de contexto y contenido. Entre los cambios contextuales se debe mencionar un ambiente normativo menos aislacionista (como resultado de la liberalización unilateral y multilateral) y un renovado interés en profundizar la integración con la economía mundial (en contraste con las políticas "autárquicas" que predominaban en el pasado). Los cambios de contenido más importantes incluyen una cobertura más amplia de temas y disciplinas (una agenda "más profunda") y el establecimiento de acuerdos norte-sur que vinculan economías con grandes disparidades de ingreso per cápita. Estas innovaciones pueden aumentar los compromisos de liberalización, pero también la fricción entre regímenes y estándares de tratamiento divergentes. Los países desarrollados también participan en la compleja red de acuerdos de comercio preferencial del "nuevo regionalismo". El caso más destacado, debido a su papel sistémico y su aporte decisivo a la creación del régimen comercial multilateral de posguerra, es el de Estados Unidos, que después de décadas de ser el paladín del multilateralismo ha adoptado la discriminación como política complementaria. ${ }^{3}$

El "nuevo regionalismo" tiene algunas ventajas con respecto a los acuerdos de comercio preferencial que se celebraban en el pasado. Algunas se relacionan con el nuevo marco normativo del comercio - por ejemplo, las políticas menos aislacionistas han bajado los costos económicos del desvío de comercio para los miembros y de la discriminación negativa para los no miembros-, mientras que otras se refieren al contenido específico del regionalismo de nuevo cuño. Varios analistas afirman que los acuerdos norte-sur permiten que las economías más pequeñas y menos desarrolladas obtengan acceso preferencial a los grandes mercados de altos ingresos. Esta ventaja no puede obtenerse mediante la liberalización unilateral y se comparte con otros cuando la liberalización es el resultado de negociaciones multilaterales. En algunas

permanecía al margen de prácticas discriminatorias, se ha unido a la tendencia global, como sugieren los pactos preferenciales firmados por Japón, la República de Corea y Singapur. Véase un análisis temprano de las características del "nuevo regionalismo" en Bouzas y Ros (1994); véase también BID (2002) y Torrent (2002).

${ }^{3}$ La Comunidad Europea tuvo una tradición de políticas comerciales preferenciales activas respecto de los países en desarrollo, en gran parte debido a las herencias de su pasado colonial. circunstancias, el acceso preferencial a los grandes mercados puede ser un poderoso incentivo a las exportaciones de los países en desarrollo. Del mismo modo, la mayor cobertura de disciplinas que caracteriza al "nuevo regionalismo" puede brindar al país en desarrollo condiciones más estables de acceso al mercado. Esto tiene particular importancia debido al tipo de instrumentos proteccionistas que se aplican en los países industrializados, como la "protección administrativa" y los estándares sanitarios, entre otros. Los acuerdos norte-sur también pueden ser un vehículo para mejorar las expectativas, ofrecer mayor certidumbre al régimen de políticas y atraer mayores flujos de inversión extranjera a los países que generalmente presentan serias restricciones de balanza de pagos (Ethier, 1998; Banco Mundial, 2000). Algunos autores también afirman que pueden alentar (o inclusive "obligar") a los países en desarrollo a adoptar instituciones características del socio más desarrollado, ayudándolo de ese modo a mejorar su desempeño económico. ${ }^{4}$

Para alcanzar estos resultados, que no son automáticos, los acuerdos norte-sur deben ofrecer una respuesta adecuada ante al menos cuatro desafíos: asegurar la reciprocidad ${ }^{5}$ efectiva; ayudar a cubrir los costos de ajuste y transición; impedir la consolidación de dinámicas de polarización y asegurar que los efectos institucionales indirectos sean positivos; y que el socio en desarrollo pueda asimilarlos de manera eficaz. Nada puede darse por sentado respecto a ninguno de ellos, por lo cual deben tratarse de manera explícita en todos los acuerdos norte-sur.

Aunque la reciprocidad es un principio fundamental, la historia demuestra que no ha sido fácil aplicarlo en el sistema de comercio multilateral, inclusive en la Ronda Uruguay que finalizó en 1994. De hecho, pese a que la agricultura fue incluida entre las disciplinas generales del Acuerdo General sobre Aranceles Aduaneros y Comercio (GATT) y las partes se comprometieron a eliminar paulatinamente las restricciones cuantitativas al comercio textil y de prendas de vestir, el Acuerdo de Marrakech, por el que se estableció la Organización Mundial del Comercio (OMC) y el proceso de instrumentación que le sucedió, causaron gran descontento en el mundo en desarrollo. Según muchas

\footnotetext{
4 Véase Schiff y Winters (2003).

${ }^{5}$ Reciprocidad es la política por la cual los gobiernos se otorgan mutuamente concesiones equivalentes, medidas según algún criterio (por ejemplo, uno de ellos reduce los aranceles u otras barreras a sus importaciones a cambio de que el socio le otorgue concesiones equivalentes en las barreras que afectan a sus exportaciones).
} 
opiniones, los países en desarrollo asumieron compromisos en algunas áreas — como la protección de los derechos de propiedad intelectual o la aplicación de disciplinas de inversión relacionadas con el comerciosin conocer totalmente sus efectos y repercusiones, por lo que la reciprocidad era casi imposible.

Vistos los antecedentes en el ámbito multilateral, cabe preguntarse qué factores podrían aumentar las posibilidades de negociaciones más equilibradas en el marco de los pactos preferenciales norte-sur. De hecho, varias características estructurales de la integración regional norte-sur parecen apuntar en dirección contraria y dificultar la reciprocidad. En primer lugar, los países industrializados generalmente tienen instituciones democráticas sólidas, que hacen que los votos de los ciudadanos pesen más en el proceso político interno que en los países en desarrollo. En parte por este motivo, las legislaturas de las democracias industrializadas tienden a desempeñar un papel más importante en el diseño de políticas y a canalizar los intereses del sector privado (colectivos o particulares) en forma más efectiva. Esta particularidad del proceso político está más marcada, porque en los países desarrollados el sector privado tiende a estar mejor organizado y a identificar y promover sus intereses estratégicos con mayor eficacia que en los países en desarrollo. En estos últimos el sector privado tiende a estar mejor organizado en torno a cuestiones "defensivas" y, por lo general, provee una frágil base para elaborar una agenda de negociación "ofensiva". Además, los actores no empresariales de los países industrializados también participan en forma más activa e informada en el proceso de elaboración de políticas, aumentando la probabilidad de que sus opiniones e intereses se reflejen en el acuerdo final.

Las perspectivas de que las negociaciones preferenciales norte-sur conduzcan a resultados que impliquen más reciprocidad, también disminuyen a raíz de que algunos temas controvertidos muy delicados para varios países en desarrollo surgen del juego de fuerzas en la economía política mundial. Por ese motivo, no está clara la manera en que las negociaciones preferenciales podrían avanzar sustancialmente hacia acuerdos comerciales más equilibrados. ${ }^{6}$ Los subsidios nacionales a los

\footnotetext{
${ }^{6}$ Los acuerdos de comercio preferencial norte-sur (entre ellos el Tratado de Libre Comercio de América del Norte o el Tratado de Libre Comercio entre la Unión Europea y México o Chile) fueron cuidadosamente concebidos para no tocar temas muy delicados para el socio desarrollado (como la agricultura de regiones templadas en el caso de la Unión Europea). Aunque esta puede ser una negociación aceptable para algunos países en desarrollo, para otros puede resultar una opción extremadamente costosa.
}

productos agrícolas de regiones templadas y la instrumentación de "medidas de alivio comercial", sobre todo derechos antidumping, son algunos de los aspectos controvertidos mencionados. Un examen superficial de los acuerdos preferenciales norte-sur que están vigentes parecería confirmar que estos temas no fueron abordados adecuadamente por los negociadores.

La probabilidad de que los acuerdos preferenciales norte-sur se basen en el principio de reciprocidad también depende de la dinámica del proceso de negociación. Algunas consideraciones de economía política sugieren que uno de los factores que influyen en la decisión de los países industrializados al seleccionar los socios para un acuerdo de comercio preferencial es la reducción al mínimo de los costos de transición y ajuste (y, en consecuencia, de la oposición política interna). En un contexto asimétrico, esto aumentará la probabilidad de que el acuerdo refleje las prioridades del socio más poderoso. Si un país industrializado suscribe sucesivos acuerdos con un país en desarrollo por vez, es muy probable que esos acuerdos no se basen en la reciprocidad. Además de las repercusiones de esta modalidad de negociación en el contenido normativo de los sucesivos acuerdos, los "costos de exclusión" para los no asociados aumentarán al mismo ritmo que la expansión de la red preferencial (ya sea mediante un acuerdo "minilateral" o un sistema de "ejes y rayos"). En el contexto actual de incertidumbre con respecto a la evolución del régimen de comercio multilateral, los "incentivos defensivos" resultantes pueden hacer que los costos de la no participación (inclusive en un arreglo no recíproco) sean insostenibles desde el punto de vista económico y político. $\mathrm{Al}$ aumentar los "costos de exclusión" percibidos también puede elevarse el "boleto de entrada" para acceder a los acuerdos y disminuir la probabilidad de acuerdos equilibrados y recíprocos. ${ }^{7}$

Los acuerdos de comercio preferencial norte-sur pueden ser un vehículo para mejorar las expectativas, brindar más estabilidad a los regímenes de política y atraer mayores flujos de inversión extranjera hacia los países en desarrollo. También pueden estimular a un país en desarrollo a perfeccionar sus instituciones y a adoptar algunas de las que predominan en los países desarrollados, mejorando de ese modo su desempeño económico. Sin embargo, estos resultados son menos

\footnotetext{
${ }^{7}$ Estas dinámicas perversas no son tomadas en consideración por los argumentos tautológicos que con frecuencia intentan explicar la conducta de gobiernos de países en desarrollo frente a acuerdos norte-sur en el hecho de que "si ellos participan voluntariamente de tales actividades ha de ser porque los beneficia".
} 
automáticos de lo que suponen los defensores más entusiastas del regionalismo norte-sur. La mayor estabilidad de los regímenes normativos será positiva sólo si las políticas subyacentes son apropiadas y sostenibles. Aunque la integración económica con un país desarrollado puede estimular la modernización institucional, la "importación" de instituciones es raramente la mejor forma de proceder, entre otras cosas, porque la eficacia de mecanismos institucionales alternativos depende del ambiente en el que estos operan (Lawrence, 1999). Esto no significa que los efectos institucionales no puedan ser positivos, sino que dependerán en gran medida de las circunstancias particulares, el ambiente interno y las políticas nacionales. Además, algunas instituciones o regímenes extranjeros pueden contraponerse abiertamente a los intereses económicos o de política del socio en desarrollo. ${ }^{8}$

Los costos de transición y ajuste para el país en desarrollo constituyen un tercer aspecto clave que el regionalismo norte-sur debe resolver. La liberalización preferencial - como cualquier proceso de liberalización- supondrá la necesidad de que las partes administren tales costos. Cuando las dotaciones de factores de producción de los socios difieren mucho, como generalmente ocurre en los acuerdos norte-sur, el patrón de especialización resultante tendrá en gran medida carácter interindustrial. En consecuencia, los precios relativos y la retribución de los factores sufrirán cambios comparativamente grandes. ${ }^{9}$ Estos cambios serán aún mayores en el socio más pequeño, resultado que para la teoría de comercio convencional es evidencia de que la mayoría de las ventajas de la liberalización favorecerán a la economía menor. Sin embargo, aunque la especialización entre sectores ofrece la posibilidad de mejorar considerablemente la eficiencia, estas mejoras son potenciales y, de materializarse, lo harán sólo a largo plazo. Durante la transición, las economías nacionales tendrán que hacer frente a los costos del ajuste.

Esta inconsistencia temporal es un importante problema de economía política, pero recibe relativamente

\footnotetext{
${ }^{8}$ La protección de los derechos de propiedad intelectual establecida originalmente en el acuerdo sobre los aspectos de los derechos de propiedad intelectual relacionados con el comercio (ADPIC) fue problemática para muchos países en desarrollo, como se reconoció oficialmente después de mucho activismo diplomático en el área de la salud pública.

${ }^{9}$ La especialización dentro de un sector o industria enfrenta menos resistencia que la especialización interindustrial, porque generalmente trae aparejados cambios menos importantes en los precios relativos. Esto, a su vez, produce menos cambios en la retribución de los factores de producción y en la distribución del ingreso.
}

poca atención en la teoría de comercio internacional convencional. También supone un gran dilema para quienes formulan las políticas en el mundo real. Los intensos debates que tuvieron lugar en el Congreso de los Estados Unidos durante la consideración del Tratado de Libre Comercio (TLC) de América del Norte —entre Canadá, México y los Estados Unidos-, y más recientemente, cuando el Congreso aprobó la ley de Promoción Comercial (TPA, por sus siglas en inglés), ponen de relieve el interés que el tema de los costos de transición y ajuste suscita en los países industrializados. ${ }^{10}$ Estos temas son aún más importantes para los países en desarrollo, donde los costos de ajuste generalmente son mayores y se dispone de menos recursos financieros, políticos e institucionales para hacer frente a sus consecuencias. Si este problema no se trata en forma cooperativa, puede conducir a un aumento de las asimetrías preexistentes, al permitir que el país desarrollado maneje de manera más eficaz sus propios costos de ajuste o inclusive transfiera algunos de ellos a su socio en desarrollo.

Por último, la existencia de fallas de política y de mercado también puede contribuir a transformar los costos de ajuste y transición en dinámicas de polarización y trayectorias divergentes. Los acuerdos preferenciales norte-sur ofrecen oportunidades de convergencia en los niveles de ingreso per cápita entre los países ricos y pobres, pero también pueden consolidar círculos viciosos de estancamiento y decadencia. De hecho, no hay razones teóricas por las que una trayectoria debiera predominar sobre la otra. Algunos autores hacen hincapié en las fuerzas que promueven la convergencia (Banco Mundial, 2000), mientras que otros recalcan la persistencia de desempeños económicos divergentes a lo largo del tiempo (como sucede con los modelos de causalidad acumulativa o las teorías de crecimiento endógeno). ${ }^{11}$ En este último caso, los "efectos de polarización" podrían acentuar las desigualdades preexistentes y hacer que los acuerdos de comercio preferencial sean insostenibles desde el punto de vista económico, político o ambos, a menos que se adopten políticas públicas activas.

\footnotetext{
${ }^{10}$ Además de definir de manera precisa los objetivos que debería perseguir el gobierno estadounidense en las negociaciones comerciales, la ley de Promoción Comercial se aprobó junto con un paquete de recursos financieros para brindar beneficios de seguridad social a los trabajadores que se quedaran sin empleo por el aumento de las importaciones.

11 Véase en Bouzas (2003) un debate sobre los efectos de las asimetrías estructurales y normativas en la integración económica.
} 
En los países en desarrollo, las fallas de los mercados financiero, de información y tecnológico son frecuentes. También hay fallas de política debidas a que las instituciones democráticas son relativamente nuevas y frágiles y tienen poca capacidad administrativa. En este contexto, las fuerzas que tienden hacia la convergencia pueden ser demasiado débiles. La Unión Europea, cuyas desigualdades de ingreso per cápita son mucho menores que en el hemisferio occidental, utilizó intensamente fondos estructurales y regionales para promover la cohesión y contrarrestar las fuerzas que tendían a la polarización. Las pruebas disponibles sugieren que, además del aporte de las transferencias financieras (un tema discutible), la modernización de las instituciones locales también desempeñó un papel clave.

En resumen, el "nuevo regionalismo" presenta ventajas en comparación con los acuerdos de comercio preferencial del pasado (muchas de ellas relacionadas con una cobertura más amplia), pero también nuevos problemas que impiden llegar a conclusiones claras sobre su superioridad. En efecto, muchos de los desafíos y las oportunidades típicas de la discriminación comercial se magnifican en los acuerdos norte-sur. Esta ambigüedad aparece en el trasfondo de la mayoría de los análisis, pero sus consecuencias raramente se analizan cabalmente. En algunas circunstancias el "nuevo regionalismo" puede traer beneficios tangibles para un país en desarrollo, como el rápido crecimiento de las exportaciones industriales en el caso de México. No obstante, la naturaleza y el alcance de esos beneficios dependerán del contenido del acuerdo, la agenda bilateral, las características estructurales de los socios y las políticas internas. Estas calificaciones parecen bastante obvias, pero se les ha dado poca importancia en el pasado y sólo recientemente - frente a la evidencia de las dificultades - comienzan a ocupar un lugar más importante en el debate de políticas públicas.

Yendo más allá del enfoque nacional, se debe recalcar que los efectos del "nuevo regionalismo" (especialmente de los acuerdos norte-sur) en los países excluidos probablemente serán adversos. Los incentivos de naturaleza defensiva resultantes pueden distorsionar las decisiones de política y desequilibrar aún más el campo de juego. Evaluar las consecuencias de este proceso desde una perspectiva "cosmopolita" —en lugar de una puramente nacional - es una tarea difícil, pero debe llevarse a cabo para analizar en forma adecuada las repercusiones del "nuevo regionalismo". Gran parte del debate acerca de si el regionalismo es un trampolín o un escollo para el multilateralismo se resume en este tema, que no es un asunto teórico, sino empírico.

\section{III}

\section{El papel de las políticas internas}

Los acuerdos de comercio preferencial, sobre todo los acuerdos norte-sur, provocaron fuertes reacciones a favor y en contra. En el debate consiguiente por lo general se ha relegado a un segundo plano el elemento clave para cosechar los frutos potenciales de la integración económica: las políticas internas. La liberalización del comercio (ya sea preferencial, multilateral o unilateral) puede aumentar la eficiencia, promover el aumento de la productividad y contribuir al desarrollo económico, pero no es una condición suficiente para el crecimiento y el desarrollo, como sugerían las recomendaciones de política simplistas que predominaron en el decenio de 1990. En forma análoga, la integración económica y los acuerdos preferenciales norte-sur pueden estimular el crecimiento y el desarrollo, pero el que lo hagan dependerá del contenido del acuerdo y de las políticas internas que lo acompañen.
Durante la década de 1990 muchos países latinoamericanos y del Caribe pusieron en marcha ambiciosos programas de liberalización, pero en la mayoría de ellos el desempeño no mejoró significativamente en términos de producto real ni de crecimiento de las exportaciones. ${ }^{12}$ Los beneficios potenciales de la liberalización comercial sólo pueden materializarse si esta se complementa con políticas internas adecuadas en el campo de la macroeconomía, el fomento de la competencia y la compensación de fallas de mercado críticas. Lo mismo ocurre con la liberalización preferencial.

El entorno macroeconómico en que tiene lugar un proceso de liberalización es fundamental para su sostenibilidad e impacto. En América Latina hay una

\footnotetext{
12 Véase un análisis más detallado en Bouzas y Keifman (2003).
} 
larga tradición de programas de liberalización del comercio que se han aplicado simultáneamente con procesos de estabilización macroeconómica basados en el uso de la tasa de cambio nominal como ancla contra la inflación. Todos ellos condujeron a la apreciación real de la moneda nacional y, con el tiempo, a crisis externas y cambios de política radicales. Estas experiencias fallidas, que en algunos países tuvieron lugar más de una vez, debilitaron el tejido productivo y redujeron su capacidad de beneficiarse de futuros episodios de liberalización comercial. Es muy difícil que las economías sujetas a crisis externas recurrentes y flujos de capital volátiles puedan sostener políticas de liberalización comercial exitosas a lo largo del tiempo y, a la vez, presentar un ritmo de crecimiento aceptable.

De hecho, para tener un desempeño económico razonable los países deben aplicar políticas cambiarias orientadas a la exportación (impidiendo la apreciación real de la moneda nacional por largos períodos de tiempo); instrumentar políticas fiscales prudentes que eviten la acumulación de excesivas deudas del sector público, y adoptar mecanismos para compensar crisis y conmociones inesperadas. En este contexto, es probable que un acuerdo de comercio preferencial que limite la capacidad de utilizar instrumentos de política, para reducir la vulnerabilidad a las perturbaciones externas (provenientes, por ejemplo, de los mercados financieros), no sea un mecanismo idóneo para la administración responsable de la macroeconomía. Por el contrario, un acuerdo que incluya mecanismos de compensación para hacer frente a crisis externas inesperadas puede aumentar las probabilidades de resultados macroeconómicos más satisfactorios. Por ejemplo, hay amplio consenso en que la ayuda financiera inmediata y cuantiosa del gobierno de los Estados Unidos a México en 1994-1995 ayudó a la economía mexicana a dejar atrás la "crisis del peso" con más rapidez. Es probable que el TLC de América del Norte haya tenido un efecto favorable en las expectativas de los inversionistas y que eso ayudara a México a superar la crisis, pero el paquete financiero creado por el gobierno estadounidense tuvo en ese período una importancia al menos similar.

En efecto, para asegurar condiciones internas que les permitan beneficiarse de la integración económica y la liberalización del comercio, los países también tienen que aplicar políticas que fomenten la competitividad y compensen las fallas de mercado. Un régimen comercial más abierto es una condición necesaria para mejorar la eficiencia económica, pero igual importancia tiene la instrumentación de políticas complementarias que permitan a los países aprovechar los beneficios de la especialización internacional. Una estrategia competitiva de este tipo debería basarse en por lo menos tres pilares: i) la construcción de infraestructura adecuada; ii) la diversificación de la estructura de producción; y iii) el desarrollo y fortalecimiento de los sistemas de innovación nacionales.

La falta de infraestructura adecuada es un factor clave que frena el comercio internacional. Muchos productos no son comercializados simplemente porque los altos costos de transporte constituyen una enorme barrera al comercio. El precio relativamente alto de los servicios también disminuye los incentivos para fragmentar el proceso de producción en diversos países, lo que limita la posibilidad de especialización intrasectorial. La ayuda externa podría contribuir mucho a mejorar la infraestructura vinculada al comercio, concentrándose en proyectos nacionales o en proyectos nacionales que tengan externalidades regionales. En los acuerdos norte-sur el problema de desarrollo de infraestructura debería resolverse de manera más fácil y efectiva que en los acuerdos sur-sur o en la liberalización unilateral o multilateral, porque una de las partes generalmente cuenta con amplios recursos financieros y administrativos que pueden canalizarse para ese fin. El papel que desempeña el gasto en infraestructura de la Unión Europea, donde las desigualdades de ingreso per cápita son mucho menores que en el hemisferio occidental, debería servir de ejemplo para promover un enfoque más eficaz al tema.

Las políticas de promoción de exportaciones pueden ayudar a diversificar la producción. Una diplomacia comercial activa que abra mercados extranjeros, descubra nuevas oportunidades y difunda información puede contribuir a acrecentar las exportaciones. Para que tales políticas sean eficaces se necesita una burocracia calificada y funcionarios públicos capaces de llevar adelante una relación de cooperación - pero independiente- con el sector privado. En consecuencia, las políticas de fomento de las exportaciones que estimulan el acceso a la información, el apoyo al comercio exterior, la asistencia financiera y las garantías de seguro pueden desempeñar un papel muy importante. Muchos de estos instrumentos e instituciones ya existen en diversos países latinoamericanos, pero todavía son ineficaces. No obstante, hay excepciones que confirman que su aporte puede ser verdaderamente significativo. En lugar de subsidios convencionales a las exportaciones (en su mayoría limitados por compromisos multilaterales), el enfoque moderno 
del incentivo a la exportación hace hincapié en el suministro eficiente de información, coordinación y otros bienes públicos.

Considerando las fallas que predominan en los mercados de tecnología, de crédito y de capital humano, las políticas tendientes a aumentar la productividad son la mejor receta para mejorar el desempeño de las exportaciones en el largo plazo. Pese a que los acuerdos de la Ronda Uruguay prohibieron los subsidios a las exportaciones no agrícolas, sí dieron luz verde a otros mecanismos internos que utilizan ampliamente los países industrializados (como los subsidios a las actividades de investigación y desarrollo). Hay tres aspectos que son críticos para cerrar la brecha que existe entre los países industrializados y los países en desarrollo en cuanto al tipo y alcance de las ayudas del sector público (CEPAL, 2002). En primer lugar, las políticas deberían promover los eslabonamientos hacia delante y hacia atrás como mecanismo para superar una estructura económica dual, en la cual las actividades modernas e integradas a la economía mundial conviven con sectores atrasados y de baja productividad. En este campo, las políticas públicas internas pueden ayudar, brindando infraestructura y coordinación orientadas a fortalecer aglomerados productivos. En segundo lugar, son necesarios organismos oficiales que puedan ayudar a las empresas locales (sobre todo pequeñas y medianas) en lo que se refiere a difusión de tecnolo- gía, innovación y desarrollo de recursos humanos. Las políticas públicas deberían concentrarse en brindar una infraestructura científica y tecnológica sólida, estimular la investigación y el desarrollo y coordinar actividades de innovación realizadas por universidades, empresas e instituciones de investigación. Por último, visto que el gasto en investigación y desarrollo como proporción del PIB es cinco veces mayor en los países industrializados que en las naciones en desarrollo, los gobiernos de estas últimas deberían considerar la posibilidad de otorgar subsidios a actividades de este tipo en el sector privado.

Ninguna de las políticas señaladas tiene el éxito garantizado, sobre todo dadas la fragilidad y debilidad institucionales que predominan en América Latina. Pero aun así es indispensable promover iniciativas adecuadas en cada una de esas áreas, si se desean obtener los potenciales beneficios de la liberalización comercial y la integración económica. Como demuestra la experiencia de México después de una década de membresía en el Tratado de Libre Comercio de América del Norte, a pesar del rápido crecimiento de las exportaciones a los Estados Unidos y el cambio en la composición de los bienes exportados, la falta de políticas internas eficaces en estas áreas fundamentales ha consolidado una economía dual, en la que las desigualdades de ingreso personal y regional han aumentado en lugar de disminuir.

\section{IV}

\section{Diez años después de Miami: ¿adónde conducen las negociaciones del ALCA?}

Cuando el proceso de negociación del ALCA comenzó en 1994, fue recibido con una mezcla de entusiasmo y escepticismo. Ambas reacciones tenían fundamento. Algunos gobiernos lo consideraban un medio para restaurar el comercio y los incentivos a la inversión erosionados por las preferencias otorgadas a México, mientras que otros - para los cuales los incentivos al comercio y la inversión no eran tan evidentes- veían en el ALCA un seguro para tener acceso estable a un gran mercado y un mecanismo para consolidar reformas económicas y mejorar las expectativas. El ALCA parecía a algunos gobiernos una oportunidad para fortalecer las relaciones hemisféricas y hacer más explícito el compromiso de los Estados Unidos en la región. Estas visiones entusiastas justifican el apoyo que la iniciativa tuvo en muchos gobiernos latinoamericanos y el intenso trabajo diplomático que muchos de ellos realizaron para incluir los temas comerciales en la agenda de la primera Cumbre de las Américas, reunión presidencial realizada en Miami en diciembre de $1994 .{ }^{13}$

\footnotetext{
${ }^{13}$ Algunas semanas antes de esa reunión, el gobierno estadounidense se inclinaba por no incluir ningún compromiso comercial específico en la declaración final. Varios gobiernos de la región se movilizaron para impedirlo, argumentando que el no asumir un compromiso explícito sobre temas comerciales quitaría relevancia a esa reunión cumbre. Véase un análisis de los primeros años de negociaciones en Bouzas y Svarzman (2001); véase también Feinberg (1997).
} 
Pero los escépticos también contaban con argumentos de peso. En efecto, las agendas, los intereses y las percepciones divergentes; las asimetrías de desarrollo y tamaño, y el problema de credibilidad que enfrentaban los negociadores estadounidenses (que carecían de un mandato del Congreso para negociar acuerdos comerciales mediante el procedimiento de la vía rápida) también eran buenas razones para el pesimismo. A pesar de estas reservas, los gobiernos más reticentes no parecían tener otra opción que seguir la tendencia mayoritaria y concentrarse en desarrollar estrategias para bloquear o demorar las negociaciones. Este mecanismo resultó favorecido por la falta de credibilidad de los negociadores de los Estados Unidos, pero a medida que pasó el tiempo hasta los países más renuentes comenzaron a prepararse para las negociaciones, organizando sus sectores públicos y promoviendo una cooperación más estrecha entre actores públicos y privados. ${ }^{14}$

Durante los tres primeros años de negociaciones los gobiernos participantes reunieron información, se conocieron unos a otros y sentaron las bases estratégicas que guiarían los acuerdos. Solamente en la cuarta Reunión Ministerial sobre Comercio, realizada en San José de Costa Rica en 1998, los ministros de comercio anunciaron los principios fundamentales y definieron la estructura que tendrían las negociaciones. ${ }^{15}$ No obstante, el conjunto de principios acordado en esa ocasión dejó varios temas sin resolver y dio lugar a distintas interpretaciones de los compromisos por las partes. ${ }^{16}$ La reunión presidencial (segunda Cumbre de las Américas) realizada en Santiago de Chile en 1998 ratificó los acuerdos alcanzados en San José y lanzó formalmente las negociaciones.

\footnotetext{
${ }^{14}$ El gobierno brasileño, uno de los participantes más renuentes en el proceso del ALCA, fue también uno de los más dinámicos en la toma de iniciativas que apuntaban a crear las condiciones internas para negociar con mayor eficacia. Véase un análisis al respecto en Da Motta Veiga (2002).

${ }^{15}$ Los principios más importantes que se acordaron fueron: i) toma de decisiones por consenso; ii) acuerdo de un solo paquete de derechos y obligaciones equivalentes para todos los firmantes ("compromiso único"); iii) participación individual o grupal en las negociaciones; iv) coherencia con la OMC; v) no exclusiones a priori en las negociaciones sobre acceso a mercados; vi) coexistencia del ALCA con procesos de integración subregionales; vii) iguales derechos y obligaciones, teniendo en cuenta las diferencias de tamaño y grados de desarrollo, y viii) inicio efectivo de las negociaciones en 1998 y conclusión a más tardar en 2004. En la reunión de San José las partes establecieron la estructura de las negociaciones: habría nueve Grupos de Negociación bajo la supervisión de un Comité de Negociaciones Comerciales formado por viceministros de comercio. Este comité se reuniría por lo menos una vez cada 18 meses. ${ }^{16}$ Un ejemplo de la ambigüedad de algunos de los principios acordados en San José fue la coexistencia de los principios de "compromiso único" y "cosecha temprana".
}

Después de la Cumbre de Santiago, el proceso del ALCA pasó a la siguiente fase, con una agenda más específica que incluía la definición de los mandatos para cada Grupo de Negociación y de los procedimientos y modalidades específicas que habrían de adoptarse en cada foro. Las partes acordaron redactar y presentar un borrador unificado a la sexta Reunión Ministerial sobre Comercio que tendría lugar en abril del 2001 en Buenos Aires. En esta reunión los ministros de comercio examinaron un largo texto "encorchetado" que consolidó los resultados —o la falta de ellosproducto del trabajo de cada uno de los nueve Grupos de Negociación. Gran parte del documento simplemente reproducía posiciones nacionales divergentes.

La séptima Reunión Ministerial sobre Comercio tuvo lugar en Quito, en noviembre del 2002, y registró modestos avances en comparación con la anterior realizada en Buenos Aires. En Quito se presentó un segundo borrador a los ministros, el Comité Técnico de Asuntos Institucionales comenzó a funcionar, se acordaron los métodos y modalidades de negociación para la siguiente fase (incluidas las modalidades para notificar aranceles básicos) y se establecieron plazos para intercambiar ofertas de acceso a los mercados (a partir del 15 de diciembre del 2002). A pesar del aparente progreso, en muchos capítulos del borrador la eliminación de corchetes fue mínima y se limitó a aspectos formales. En la práctica, los textos encorchetados que revelaban considerables diferencias de opinión se mantuvieron inalterados iguales.

La Reunión Ministerial sobre Comercio de Quito también planteó dudas con respecto a la capacidad de cumplir con los plazos establecidos, sobre todo para la presentación de ofertas de acceso a los mercados. En efecto, el lanzamiento de las negociaciones en cinco de los grupos (agricultura, acceso a mercados, compras del sector público, servicios e inversiones) y el establecimiento de un cronograma para intercambiar ofertas se realizaron sin conciliar diferencias fundamentales con respecto a los métodos y modalidades que cada grupo de negociación habría de adoptar. La estructura del capítulo de servicios y su relación con el capítulo de inversión, por ejemplo, quedaron sin resolver. ${ }^{17}$ Por otra parte, hubo desacuerdos sobre la forma

\footnotetext{
${ }^{17}$ Faltó decidir, por ejemplo, si las ofertas en el sector de servicios se harían siguiendo los criterios de listas negativas o positivas, o si las ofertas relacionadas con la inversión extranjera directa en servicios se incluirían en el capítulo de inversiones o en el de servicios (en la modalidad de "presencia comercial", según la jerga del Acuerdo General sobre el Comercio de Servicios). Para más detalles véase http://www.ub.es/obsglob/Seriemercosur-.html.
} 
de presentar concesiones arancelarias en el capítulo correspondiente a bienes. ${ }^{18} \mathrm{El}$ contenido operacional del principio de tratamiento especial y diferencial también fue objeto de controversia. ${ }^{19}$

Las ofertas realizadas a partir de diciembre del 2002 reflejaron esas ambigüedades. Casi todos los países presentaron ofertas relativas a bienes y servicios antes de la fecha establecida (15 de febrero del 2003), pero no ocurrió lo mismo en el caso de los capítulos de inversión y compras del sector público. Los grupos de países que presentaron ofertas conjuntas (el Mercosur, la Comunidad Andina y el Mercado Común Centroamericano) lo hicieron con diferente formato, cobertura y estructura, situación que reflejó las dificultades para encontrar un enfoque común. Estados Unidos, a su vez, presentó cuatro ofertas distintas de acceso al mercado, según el grupo de países destinatarios. Todos los demás participantes realizaron una única oferta, indicando la posibilidad de algún tipo de tratamiento especial para las pequeñas economías. Las ofertas relativas a los servicios e inversiones también se realizaron con distintos enfoques estructurales.

En resumen, poco antes de la octava Reunión Ministerial sobre Comercio, efectuada en noviembre del 2003 en Miami, las negociaciones del ALCA presentaban muchos aspectos sin resolver. La falta de ofertas por parte de Argentina y Brasil en sectores como compras del sector público, servicios e inversiones reflejaron una creciente preocupación por el equilibrio general de las negociaciones. En efecto, la renuencia de los Estados Unidos a tratar ciertos temas en el ámbito hemisférico (entre ellos el antidumping o los subsidios agrícolas), ya fuera por considerarlos inadecuados para tratamiento preferencial o de naturaleza sistémica, hizo que se retiraran de la agenda del ALCA temas considerados de interés "ofensivo" para ese país (precisamente inversión, servicios y compras del sec-

\footnotetext{
${ }^{18}$ No se decidió si la presentación de ofertas de acceso a mercados en el sector de bienes se haría sobre la base del principio regional de nación más favorecida o si incluiría diferentes tratamientos según los países o grupos de países. Véase http://www.ub.es/obsglob/ Semercosur-.html

${ }^{19}$ La declaración ministerial de Quito reafirmó algunas condiciones para el avance de las negociaciones, que pusieron de manifiesto las preocupaciones de los participantes. Algunos de los problemas principales eran la necesidad de "realizar avances continuos, equilibrados y sustanciales en todos los ámbitos sujetos a negociación", tener en cuenta los diferentes grados de desarrollo y de tamaño de los países y vincular las negociaciones del ALCA con los avances registrados en la Ronda de Doha.

${ }^{20}$ Con respecto al potencial aporte del ALCA a la promoción de cambios de política en áreas delicadas para los Estados Unidos, cabe señalar que los países del hemisferio occidental, que todavía
}

tor público). ${ }^{20}$ En consecuencia, a mediados del 2003 el Mercosur presentó una propuesta formal para continuar las negociaciones por tres vías paralelas: una vía bilateral en el "formato 4+1" (los países miembros del Mercosur y Estados Unidos), una vía ALCA y una vía multilateral. Cada una de estas vías cubriría una gama diferente de temas y el ALCA tendría una agenda mucho menos ambiciosa que en su concepción original. ${ }^{21}$

La reducción de la amplitud y el alcance del ALCA se unió a otra tendencia firmemente establecida en los últimos años: la progresiva "bilateralización" del proceso de negociación. Desde 1994 se ha desarrollado en forma simultánea y paralela al ALCA un proceso estratificado de negociaciones bilaterales y "minilaterales", en que las consideraciones relacionadas con el acceso al mercado estadounidense han desempeñado un papel clave. Como parte de este proceso, y después de una prolongada demora, el gobierno estadounidense firmó un tratado de libre comercio con Chile y concluyó negociaciones con los miembros del Mercado Común Centroamericano. También lanzó negociaciones con la República Dominicana, Perú, Colombia, Ecuador y Bolivia. Desde el punto de vista de los intereses de los Estados Unidos, estas negociaciones secuenciales apuntaron a consolidar gradualmente una agenda y una arquitectura coherente con sus objetivos de negociación más amplios. Esta estrategia no fue sólo de los Estados Unidos. En efecto, el Mercosur intentó con mucho menos éxito establecer un área de libre comercio en América del Sur, mientras que México y Chile consolidaron su papel como centros de conexiones en el sistema de "ejes y rayos" que se estaba construyendo.

La Reunión Ministerial sobre Comercio celebrada en Miami no aclaró las dudas que existían sobre las perspectivas del ALCA, y de hecho suscitó otras nuevas. Esta reunión no fue un fracaso total, pero repitió una característica estándar de las negociaciones del ALCA: posponer los temas más delicados, a pesar de que sólo faltaban 12 meses para la fecha en que deberían concluir las negociaciones. En la práctica, la reunión de

no han comenzado negociaciones preferenciales bilaterales con ese país, representaban en el 2001 alrededor del $6 \%$ de las exportaciones estadounidenses totales, en comparación con el 44,3\% correspondiente a todo el hemisferio.

${ }^{21}$ Véase: http://www.ub.es/obsglob/Semercosur-.html. En esa misma ocasión 13 países (12 latinoamericanos y Canadá) presentaron un documento que apoyaba el mantenimiento de una agenda ambiciosa. Uruguay también presentó un texto que trataba de compatibilizar el "enfoque original" con cierto grado de flexibilidad para tomar en consideración especificidades nacionales. 
Miami formalizó lo que ya era un hecho: que el ALCA, en caso de llegarse a un acuerdo, sería mucho menos ambiciosa de lo que se imaginó en un principio. Esta versión restringida del ALCA puede ser funcional para varias de las partes clave, aunque algunas de ellas se opongan formalmente a esa arquitectura.

El compromiso de Miami ${ }^{22}$ —redactado por negociadores estadounidenses y brasileños — dio lugar a un acuerdo en dos niveles. El primero incluye "un conjunto común y equilibrado de derechos y obligaciones aplicables a todos los países", mientras que el segundo prevé "beneficios y obligaciones adicionales" para aquellos países o grupos de países dispuestos a negociar compromisos más profundos de acceso al mercado o disciplinas más estrictas. El primer nivel común incluiría derechos y obligaciones en las nueve áreas de negociación, sin exclusiones. No obstante, a falta de un acuerdo para elaborar reglas específicas (y más profundas) en todos estos temas, los acuerdos resultantes

\section{$\mathrm{V}$}

\section{Conclusiones}

Aunque las negociaciones todavía no han finalizado, el proceso de negociación del ALCA demuestra las dificultades que existen para llegar a acuerdos recíprocos de comercio preferencial norte-sur. De hecho, el ALCA que está comenzando a surgir después de una década de negociaciones plantea muchos problemas. La mejor garantía para lograr un acuerdo más equilibrado y recíproco sería mantener las negociaciones emprendidas en un marco "plurilateral" (el espíritu original del concepto de "compromiso único"). Sin embargo, las asimetrías del proceso de negociación le dieron irreversiblemente otro rumbo.

Después de una década de negociaciones, la hipótesis de un ALCA equilibrado y amplio que conduzca a una transacción aceptable para todas las partes involucradas parece estar fuera de alcance. Esto se debe a la naturaleza de la agenda y a los diferentes puntos de vista acerca de su instrumentación (varias partes mostraron un interés limitado en un acuerdo amplio). La interdependencia de algunos de los temas de nego-

\footnotetext{
22 Declaración Ministerial del 20 de noviembre del 2003 (Área de Libre Comercio de las Américas, octava Reunión Ministerial sobre Comercio, Miami).
}

podrían simplemente reproducir los compromisos ya asumidos en la OMc. En ese caso, la naturaleza del proceso del ALCA sería cuestionada seriamente. El contenido del acuerdo general no se especificó en la Declaración Ministerial debido a que las partes no llegaron a un consenso (situación que continúa a fines del 2004).

Tampoco se aclaró la relación entre el acuerdo hemisférico y los acuerdos bilaterales o multilaterales. Una alternativa podría ser adoptar una arquitectura similar a la del GATT anterior a la Ronda Uruguay, en la que un acuerdo multilateral con derechos y obligaciones para todos los firmantes convivía con códigos de conducta de adhesión voluntaria. Otra alternativa podría ser un acuerdo general multilateral que diera cobertura a la red de acuerdos bilaterales y minilaterales existentes. En este último caso el ALCA recordaría la arquitectura de la Asociación Latinoamericana de Integración (ALADI), pero con una gran diferencia: incluiría a los Estados Unidos y Canadá.

ciación y el escenario multilateral también impiden avanzar en esos temas con más rapidez en el acuerdo, a menos que prevalezca una agenda sesgada. En este contexto, como señaló el representante de comercio estadounidense después del fracaso de la Conferencia Ministerial de la OMC en Cancún, en 2003, Estados Unidos seguirá avanzando con su estrategia de "liberalización competitiva", celebrando acuerdos con aquellas partes que estén listas para hacerlo. Este marco profundiza la naturaleza asimétrica de las negociaciones comerciales hemisféricas y reduce la probabilidad de acuerdos comerciales recíprocos.

La hipótesis más probable es que el ALCA tome la forma de un acuerdo de cobertura limitada, con la modalidad de "dos niveles" acordada en Miami. Sin embargo, dadas las dificultades para concordar sobre lo que debería incluirse en el acuerdo marco, es muy posible que este termine siendo un conjunto, muy poco exigente, de principios generales. Este "mal acuerdo", no obstante, puede ajustarse a los intereses de un mayor número de socios de lo que se imaginó inicialmente.

En efecto, un acuerdo muy poco exigente no sería contrario a la estrategia comercial estadounidense de seguir el camino bilateral para avanzar en su agenda 
comercial. En este contexto, los negociadores estadounidenses continuarán eligiendo socios que ofrezcan menos resistencia a sus demandas y cuyas exigencias sean menos conflictivas para la economía política interna de los Estados Unidos. Esto les permitiría continuar promoviendo sus objetivos comerciales con un costo político interno relativamente bajo. Para los países que se han convertido en centros de conexiones hemisféricos, un acuerdo menos ambicioso puede ser un arreglo razonable para prolongar los beneficios de la discriminación positiva. A su vez, los países más renuentes (como Brasil) pueden encontrar en este contexto una alternativa para posponer la discusión de los temas más complejos implícitos en un acuerdo nortesur. Sin embargo, es preciso sopesar también los efectos de la discriminación negativa en los mercados del hemisferio occidental y el aumento de los costos de exclusión. En el mediano plazo, esto difícilmente puede considerarse una alternativa aceptable, a menos que la Ronda de Doha registre avances inesperados.

Es probable que la compleja estructura de comercio que surgirá en el hemisferio occidental aumente el sesgo mercantilista implícito en las negociaciones comerciales, desequilibrando aún más un campo de juego estructuralmente asimétrico. Considerando la fragilidad de las disciplinas que rigen los acuerdos de comercio preferencial en la OMC, las perspectivas del regionalismo norte-sur y su complementariedad con el régimen de comercio multilateral no pueden más que generar serias preocupaciones.

(Traducido del inglés)

\section{Bibliografía}

Baldwin, R. (1993): A Domino Theory of Regionalism, Working Paper, $N^{\circ} 4465$, Cambridge, Massachusetts, National Bureau of Economic Research.

Banco Mundial (2000): Trade Blocs, Nueva York, Oxford University Press.

Bhagwati, J. (1993): Regionalism and multilateralism: an overview, en J. de Melo y A. Panagariya (comps.), New Dimensions in Regional Integration, Londres, Centro de Investigación sobre Políticas Económicas.

BID (Banco Interamericano de Desarrollo) (2002): Más allá de las fronteras: el nuevo regionalismo en América Latina, Washington, D.C.

Bouzas, R. (2003): Mecanismos para compensar los efectos asimétricos de la integración regional y la globalización: el caso del MERCOSUR, documento presentado en el seminario "Enfrentar los desafíos del desarrollo regional en América Latina y el Caribe" de la Asamblea de Gobernadores del BID (Milán, marzo del 2003).

Bouzas, R. y J. Ros (1994): The North-South variety of economic integration: issues and prospects for Latin America, en R. Bouzas y J. Ros (comps.), Economic Integration in the Western Hemisphere, Notre Dame, University of Notre Dame Press.

Bouzas, R. y S. Keifman (2003): Making trade liberalization work, en P.P. Kuczyinski y J. Williamson (comps.), After the Washington Consensus: Restarting Growth and Reform in Latin America, Washington, D.C., Instituto de Economía Internacional.

Bouzas, R. y G. Svarzman (2001): El área de libre comercio de las Américas: ¿dónde está y adónde va?, Boletín informativo Techint, $\mathrm{N}^{\mathrm{o}}$ 306, Buenos Aires, Organización Techint, abriljunio.
CEPAL (Comisión Económica para América Latina y el Caribe) (2002): Globalización y desarrollo, LC/G.2157(SES.29/3), Santiago de Chile, CEPAL.

Da Motta Veiga, P. (2002): O policy-making da política comercial no Brasil: os caminhos da transiçao, El proceso de formulación de la política comercial. Nivel uno de un juego de dos niveles: estudios de países en el Hemisferio Occidental, Buenos Aires, Instituto para la Integración de América Latina y el Caribe (INTAL).

Ethier, W.J. (1998): The new regionalism, The Economic Journal, vol. 108, Oxford, Reino Unido, Blackwell Publishing, julio.

Feinberg, R. (1997): Summitry in the Americas, Washington, D.C., Instituto de Economía Internacional.

Lawrence, R. (1999): Regionalism, multilateralism, and deeper integration: changing paradigms for developing countries, en M. Rodríguez Mendoza, P. Low y B. Kotschwar (comps.), Trade Rules in the Making. Challenges in Regional and Multilateral Negotiations, Washington, D.C., Brookings Institution.

López Córdova, J.E. (2001): NAFTA and the Mexican Economy: Analytical Issues and Lessons for the FTAA, Buenos Aires, Instituto para la Integración de América Latina y el Caribe (INTAL).

Schiff, M. y A. Winters (2003): Regional Integration and Development, Washington, D.C., Banco Mundial.

Torrent, R. (2002): Regional cooperation within the multilateral system of rules: elements for a discussion from a legal, institutional and political perspective, documento presentado en el taller "The Evolving wTO Regime and Regional Economic Cooperation: Implications for Northeast Asia" (Seúl, República de Corea, 13 y 14 de septiembre), Korean Development Institute/Observatory of Globalization. 